\title{
Intento de privatización de espacios urbanos en el contexto de las políticas neoliberales: el caso de la Ciudad de México (2000-2018) ${ }^{+}$
}

\author{
OCTAVIO ALONSO SOLÓRZANO TELLO* \\ Benemérita Universidad Autónoma de Puebla \\ telloctavio2018@yahoo.com
}

\author{
TERESA DE JESÚS PORTADOR GARCÍA** \\ Benemérita Universidad Autónoma de Puebla \\ tportadorgarcia@yahoo.com
}

https://doi.org/108800/rcpg.201801.003

\section{RESUMEN}

El artículo analiza cómo se ha tratado de imponer la versión espacial y territorial del modelo neoliberal en la Ciudad de México, caracterizada por políticas urbanísticas verticales, reestructuración urbana e implementación de proyectos por parte de inmobiliarias, empresas nacionales y transnacionales, respaldadas por distintos niveles de gobierno y partidos políticos. Además, centra su atención en las "zonas de desarrollo económico y social» (Zodes) y sus efectos sociales, económicos, políticos, culturales y ambientales. Reflexiona en torno a los mecanismos y acciones colectivas desplegados por los habitantes, afectados y pueblos originarios para detener y cancelar los proyectos, y examina los impactos de los sismos de septiembre de 2017, que han agravado los grandes problemas urbanos.

Palabras clave: reformas neoliberales, ciudad neoliberal, espacios urbanos, acción colectiva, Ciudad de México.

+ Recibido el 15 de abril de 2018; aceptado el 27 de noviembre de 2018.

* Investigador-catedrático en la Benemérita Universidad Autónoma de Puebla (BUAP). Doctor en Ciencias Sociales con especialidad en Relaciones Internacionales por la Universidad Autónoma Metropolitana Unidad Xochimilco/México (UAM-X).

** Doctora en Antropología por la Universidad Nacional Autónoma de México (UNAM). 


\title{
Attempt to privatize urban spaces in the context of neoliberal policies: the case of Mexico City (2000-2018)
}

\begin{abstract}
The article analyzes the initiatives that attempted to impose a spatial and territorial version of the neoliberal model in Mexico City, characterized by vertical urban policies, urban restructuring and implementation of projects by real estate companies, national and transnational companies, and supported by different levels of government and political parties. It focuses on the Economic and Social Development Areas and their social, economic, political, cultural and environmental effects. The article reflects on the mechanisms and collective actions deployed by the city's inhabitants to stop and cancel the projects, in particular those actions led by citizens affected by these reforms and native peoples. It also examines the impact of the September 2017 earthquakes, which aggravated some important urban problems.
\end{abstract}

Keywords: neoliberal reforms, neoliberal city, urban spaces, collective action, Mexico City. 


\section{INTRODUCCIÓN}

Con la instauración del neoliberalismo en México, a partir de 1982, asistimos al incremento exponencial de planes, proyectos y políticas urbanísticas que impactan espacios urbanos y territorios, provocando la movilización de la sociedad civil en la Ciudad de México $(\mathrm{CDMX})^{1}$ debido a las formas en que se intentan imponer dichos planes y proyectos. En algunos casos, la presión social como parte de las acciones colectivas ha sido pieza clave en la suspensión temporal y/o cancelación de megaproyectos que - para el caso que abordaremos- la retórica gubernamental clasifica como «suspendidos o cancelados». No obstante, a pesar de ser declarados de tal forma, al poco tiempo dichos proyectos se reactivan para intentar imponerlos nuevamente a la ciudadanía.

Por una parte, se define que los proyectos que presentan el rostro urbanístico y espacial del modelo neoliberal se caracterizan por la apropiación de vastos espacios y territorios urbanos. Donde participan activamente inmobiliarias, empresas nacionales y transnacionales que, con la anuencia del Gobierno mexicano en sus tres niveles (federal, estatal y delegacional) y de los partidos políticos (ya que estos muchas veces respaldan y promueven la aplicación de megaproyectos y modelos urbanísticos privatizadores), excluyen, expulsan y segregan espacialmente a los habitantes de la Ciudad de México.

Estas características reflejan los cambios y dinámicas por los que pasan la mayoría de las urbes en el mundo desde el proceso de globalización de corte neoliberal.

Cabe precisar que el Gobierno mexicano, en sus tres niveles (federal, estatal y delegacional), no propone políticas o planes que regulen el movimiento del mercado inmobiliario en las ciudades de otro corte diferente al neoliberal. Asimismo, el tema tampoco está priorizado en la agenda de los planes de los partidos políticos. Es más, muchos de los megaproyectos y modelos urbanísticos de este tipo son respaldados por los partidos.

Respecto a ciertas investigaciones sobre ciudades, algunos autores han propuesto la categoría analítica «ciudad neoliberal» (Vizcaíno y Vizcaíno, 2018; Monreal, 2016; Garrón, Gómez, Sánchez y Mato, 2016), precisamente para explicar modelos urbanísticos con rostro neoliberal en otras latitudes.

\footnotetext{
1 El cambio de nombre de Distrito Federal a Ciudad de México se propuso en febrero de 2016 en el contexto de la nueva constitución de la ciudad. Sin embargo, al cierre de este artículo se sigue debatiendo en la Asamblea Legislativa la propuesta. En este trabajo utilizaremos el término delegaciones, aunque, si entra en vigor la nueva constitución de la ciudad, se les denominará municipios. Cabe decir que con el cambio de gobierno en la Ciudad de México en julio de 2018, el anterior gobierno deshabilitó y retiró de su página web la escasa información sobre las Zodes.
} 
En otra línea analítica encontramos a Theodore, Peck y Brenner (2009), Escolano, López y Pueyo (2018), Romero, Brandis y Melo (2015), que han denominado a esas nuevas dinámicas «urbanismo neoliberal», caracterizándolo a partir de la fragmentación espacial y el tejido urbano, así como la polarización socioespacial a distintas escalas. Para Theodore et al. (2009) el neoliberalismo plasmado en proyectos lleva implícito una reestructuración urbana.

América Latina no ha estado exenta de estas dinámicas y, a diferencia de Europa, presenta elementos que responden a particulares procesos históricos, sociales, políticos y culturales, y a la implementación del modelo neoliberal en la década de 1970. Las disciplinas que tienen como objeto de estudio a la ciudad han contribuido a explicar semejanzas, diferencias y variadas formas que el neoliberalismo ha tomado en las urbes latinoamericanas (Hidalgo y Janoschka, 2014; Cuervo, 2012; De Mattos, 2012). Para el caso chileno, es relevante el estudio de Rodríguez, Saborido y Segovia (2012). Hidalgo y Janoschka (2014) explican que por la aplicación temprana de reformas neoliberales en América Latina se privatizaron los servicios, lo que tuvo consecuencias en la falta de planeamiento por parte del Estado de la infraestructura urbana básica y de la vivienda (Hidalgo y Janoschka, 2014, p. 18).

En la reconfiguración de las cartografías latinoamericanas se encuentra la Ciudad de México, ya que, por la cantidad de población, ubicación geográfica, particularidad geológica y climática, es una zona altamente sensible a fenómenos naturales. Se debe tener en cuenta que la Ciudad de México presenta ciertas características geográficas y geológicas, por ejemplo, está asentada sobre un lago, presenta sobreexplotación de mantos acuíferos, hundimientos, vulnerabilidad a los sismos, aunado a su cercanía con el volcán Popocatépetl.

Por ello, el artículo busca explicar cómo las reformas de corte neoliberal afectan la política urbana de forma vertical. Se entiende como vertical en el sentido de implementación de políticas de arriba hacia abajo, impulsadas por iniciativa privada y gobiernos hacia la población. Se busca responder las siguientes interrogantes: ¿Cuál es el efecto del neoliberalismo en su versión urbanística, espacial y territorial en la Ciudad de México en los primeros dieciocho años del siglo XXI? ¿Qué acciones colectivas han desplegado los habitantes? ¿Qué son las Zodes y cómo se están implementando? ¿Qué relación guardan los sismos del año 2017 con respecto al boom inmobiliario?

Se plantea que las reformas neoliberales en México se extendieron no solo en el ámbito económico, sino también en el espacial y en el territorial. Con el objetivo de reflexionar estos fenómenos, el artículo muestra y analiza las políticas de privatización de espacios urbanos en la Ciudad de México. Se utilizan 
las categorías analíticas «neoliberalismo» y «ciudad neoliberal» para abordar el fenómeno y explicarlo, aunado a propuestas conceptuales del espacio y del territorio que han aportado los geógrafos Santos $(2008,2009)$ y Raffestin (1979) desde la concepción de lugares apropiados y disputados por distintos actores. La metodología presencial que combina la investigación in situ, centrada en la observación directa y participante, se articuló a la revisión hemerográfica y la interpretación de fuentes bibliográficas, electrónicas, documentos, dictámenes, leyes e iniciativas sobre algunos megaproyectos que se están intentando implementar.

El artículo se estructura en cuatro apartados. En el primero, se explica cómo gobiernos, inmobiliarias y empresas han implementado estrategias de corte neoliberal en su versión espacial en México y en otras latitudes; se presenta una definición del neoliberalismo aplicado al caso mexicano. El segundo apartado, muestra las conceptualizaciones que han realizado algunos autores del espacio y del territorio, asimismo se discute en torno a lo que se ha definido teóricamente como «ciudad neoliberal». El tercer apartado, centra su atención en los proyectos que han impactado a la metrópoli. Examina los intentos de implementación de las zonas de desarrollo económico y social (Zodes), las políticas urbanísticas verticales, la reestructuración urbana y sus efectos sociales, económicos, políticos, culturales y ambientales. Se realiza un análisis de las estrategias y las acciones colectivas desplegadas por los habitantes para la defensa de sus espacios públicos y privados, cuya presión ha logrado cancelar y suspender proyectos. El cuarto apartado, aborda las recientes afectaciones provocadas por los sismos de septiembre de 2017 en la Ciudad de México, mostrando que el boom inmobiliario fue un factor determinante en el incremento de los estragos provocados por el fenómeno natural, agudizó los problemas urbanos y la expulsión de habitantes de sus viviendas. El artículo cierra con reflexiones finales.

\section{EL NEOLIBERALISMO EN LOS ESPACIOS Y TERRITORIOS URBANOS}

Una mirada de amplio espectro permite sugerir que la apertura económica en las urbes ha generado profundas transformaciones económicas, políticas, sociales, culturales y ambientales, con importantes reordenamientos y reestructuraciones territoriales y espaciales en México, y en muchas metrópolis y ciudades medianas del mundo. Por ejemplo, Garnier (2015) analiza el neoliberalismo en el modelo urbano en Francia, implementado desde la década de 1980, caracterizado por proyectos espectaculares y costosos que han originado polarización socioespacial, desarrollo desigual y combinado, así como 
jerarquización de espacios; es decir, la lógica social del neoliberalismo se ha materializado en el espacio. Para el caso de España, Romero, Brandis y Melo (2015, p. 369) advierten que el giro neoliberal de las políticas para la ciudad se concreta desde la segunda mitad de la década de 1990.

Desde la década de 1980, América Latina también ha sido impactada por la ola neoliberal. Así, planes, megaproyectos, iniciativas y políticas urbanísticas son una manifestación de ello. Rodríguez y Rodríguez (2012, pp. 101, 105) analizaron el caso de Santiago de Chile de 1999 a 2008, mostrando la discontinuidad y continuidad de la gestión urbana en ese periodo. Fue en este país donde se aplicaron por primera vez las políticas de ajuste estructural a nivel continental, que implicaron el desmantelamiento de lo público, la reconstrucción espacial de la producción y la modificación de las condiciones de vida ${ }^{2}$. La continuidad de estas políticas se expresa en la construcción, en los últimos veinte años, de autopistas de cuota, túneles, megaproyectos, malls y nuevos edificios inteligentes.

El modelo neoliberal busca transformar, pulverizar y adecuar espacios y territorios urbanos con la intención de introducirlos al circuito de consumo de bienes y servicios, para extraer y aprovechar de manera intensiva y con tecnología de punta grandes cantidades de recursos naturales (agua, minerales, petróleo, maderas, especies endémicas y no endémicas de flora y fauna) y dar un uso mercantil a espacios públicos y asentamientos humanos. Desde la perspectiva de Beck:

El neoliberalismo reina no solo en las gerencias de los consorcios que operan a escala mundial y en las organizaciones económicas globales, como el Fondo Monetario Internacional y el Banco Mundial. También reina y domina dentro de los partidos, parlamentos y gobiernos, cosa fácilmente observable en el hecho de que en algunas cuestiones claves (como política económica, laboral, educativa y social) los contrastes entre los partidos políticos de todo el mundo se han diluido. En este sentido, los diversos partidos se vacían programáticamente $y$, tras la fachada inmutable de sus nombres, se transforman más o menos en sucursales de una ideología política: el neoliberalismo (2004, p. 126).

Definimos a este modelo neoliberal desde sus propias particularidades, entre las cuales destacamos las privatizaciones de empresas paraestatales y reformas estructurales: energética, fiscal, financiera, laboral, educativa y salud. En México se materializó en la concentración del ingreso que genera pobreza y la orientación a las exportaciones en detrimento del mercado interno, medidas

\footnotetext{
2 Al inicio de la dictadura de Pinochet se instauraron las bases del neoliberalismo en Chile, el cual continúa hasta el día de hoy.
} 
promocionadas y respaldadas por el Fondo Monetario Internacional (FMI), el Banco Mundial (BM), el Banco Interamericano de Desarrollo (BID) y la Organización para la Cooperación y el Desarrollo Económico (OCDE). En su versión territorial, se ha plasmado en planes de infraestructura, hidroeléctricas, termoeléctricas, gasoductos, plantas eólicas, basureros radioactivos, desarrollos turísticos, aeropuertos, presas, campos de golf, minerías a cielo abierto, acueductos, desarrollos inmobiliarios, sistemas ferroviarios y nuevas planeaciones urbanas como las Zodes, este último megaproyecto se pretende implementar y construir en toda la Ciudad de México 3 .

Los proyectos neoliberales tienen fases de planeación, elaboración e implementación. En la clasificación y segmentación de territorios y espacios urbanos no se considera la posesión, pertenencia, historia y cultura de los habitantes, quienes son despojados de sus viviendas para construir condominios, torres comerciales y departamentales, donde las empresas constructoras e inmobiliarias se llevan jugosas ganancias. En el otro extremo, los espacios públicos, parques, lugares de esparcimiento, jardines, deportivos, canchas deportivas, entre otros, son privatizados, explotados e integrados a la lógica del mercado, ponderando la especulación y la mercantilización.

Por otra parte, los gobiernos benefician a empresas nacionales y transnacionales exentándolas del pago de impuestos y servicios (agua, luz, vigilancia, predial) como una medida para incentivar su instalación y su expansión. Mientras tanto, estas sobornan a políticos y autoridades de todos los niveles como un mecanismo para cambiar reglamentos, normativas y leyes en todo el país. La información de proyectos, reformas e iniciativas de ley se otorga a cuenta gotas a los afectados, pueblos originarios ${ }^{4}$ y población urbana, dependiendo del grado de presión social que ejerzan hacia las autoridades, contraviniendo lo señalado en leyes internacionales que enfatizan el derecho a la información y consultas no amañadas a la población afectada.

\footnotetext{
3 La Ciudad de México cuenta con las siguientes delegaciones: Benito Juárez, Tlalpan, Xochimilco, Coyoacán, Iztapalapa, Venustiano Carranza, Cuajimalpa, Magdalena Contreras, Azcapotzalco, Cuauhtémoc, Miguel Hidalgo, Iztacalco, Milpa Alta, Gustavo A. Madero, Tláhuac y Álvaro Obregón.

4 Los pueblos originarios de la Ciudad de México son aquellos asentados desde la época prehispánica en la zona que hoy ocupa la urbe. De raigambre indígena, se caracterizan por su particular cosmovisión mesoamericana, por mantener viva la tradición festiva de las mayordomías y organizarse religiosamente en torno al culto a los santos y vírgenes católicos. Cabe decir que, estos pueblos fueron absorbidos por la mancha urbana, pero se resisten a perder cultura y religiosidad. Son una muestra de la permanencia y la expresión de la cosmovisión indígena.
} 
La negativa de las autoridades para otorgar información a habitantes y afectados genera sentimientos de agravio y posibilita lo que Solórzano y Portador definen como mecanismos que detonan las acciones colectivas:

[...] para que se forje una acción colectiva deben existir ciertos componentes sociales como los objetivos y problemas comunes, los agravios compartidos, los lazos de solidaridad, los mecanismos y las soluciones para enfrentar las problemáticas, y por supuesto los recursos en disputa (2016, p. 58).

\section{ESPACIO Y TERRITORIO EN LA CIUDAD NEOLIBERAL}

A través de la historia, el hombre ha explotado de manera irracional la naturaleza utilizando la técnica, praxis encaminada a transformar espacios y territorios. Santos $(2008$, pp. 147,150$)$ propone que el espacio es modificado por el hombre a través del trabajo, bajo esta premisa integra la noción de construcción social del espacio. Desde la geografía humana, Raffestin (1979) señala que en el espacio se proyecta trabajo, energía e información, revelando relaciones marcadas por el poder. Apunta que cualquier proyecto en el espacio se expresa como una representación y revela la imagen deseada del territorio como lugar de relaciones. Así, los espacios están imbricados de múltiples relaciones: hombre/ naturaleza, hombre/cultura, entre otros. En esos conjuntos de puntos, que son también localizaciones, es donde se reagrupan los individuos y los grupos, se construye toda la existencia, ya sea de ciudades, pueblos, capitales o metrópolis.

Santos (2008, p. 153), también propone el espacio como relación social, señalando que debe considerarse el conjunto de relaciones realizadas a través de funciones y de formas que se presentan como testimonio de una historia escrita por procesos del pasado y del presente, y por una estructura representada por relaciones sociales que están aconteciendo delante de nuestros ojos y se manifiestan a través de procesos y funciones. Para Raffestin (1979) todos somos actores, en tanto producimos territorio en diversos grados, momentos y lugares. Esta producción se inscribe perfectamente en el campo de poder al interior de las relaciones sociales.

El territorio es un elemento nodal en la identidad de los grupos humanos, en tanto espacio apropiado y significado. Nos referimos a las prácticas colectiva y cotidiana que dan sustento a la memoria colectiva, a la historia, a la cultura y a las identidades. Otra mirada es la que ofrecen Romero, Brandis y Melo:

El territorio se concibe como un simple soporte para dinamizar la actividad económica, [...] donde los agentes privados obtienen inmensas plusvalías derivadas de su renta por la reclasificación de terrenos, su urbanización y construcción. [...] uno de los pilares 
para llevar a cabo las políticas neoliberales ha sido la liberalización del suelo, esto es, la declaración de todo el suelo no protegido como urbanizable (2015, p. 372).

En este sentido, empresas nacionales y transnacionales poseen variados mecanismos (humanos, materiales, logísticos, económicos y tecnológicos) para extraer y explotar, adecuar espacios urbanos y territorios, extraer ganancias, excluyendo a habitantes. Utilizan mecanismos para posicionarse en el mercado mundial, respaldados y protegidos legalmente por los diferentes niveles de gobierno. En opinión de Santos (2009, p. 23), el sistema obedece a las multinacionales. Esa forma de universalización altera las dimensiones geográficas de la actividad humana. Cuando la división del trabajo y la cooperación perversa, ocasionadas por ella, se extienden a escala planetaria, el mundo como espacio se torna en un espacio global.

Las afectaciones originadas por empresas nacionales y transnacionales pueden ser permanentes. Una vez que degradan el medio ambiente y generan problemas en la salud de la población, retiran sus capitales para posicionarse en otro espacio dentro o fuera del país. La presencia de estas empresas tiene implicaciones a nivel societal, en la transformación de espacios públicos, en los ámbitos económico, laboral, cultural, ambiental, en la salud, en la destrucción del mercado interno, así como en la modificación de los paisajes urbanos y rurales. Externalidades negativas que no se reflejan en los estudios de impacto ambiental, presentados para justificar la instalación de megaproyectos y reestructuraciones urbanas.

El resguardo y defensa de los espacios urbanos y públicos sobrepasan la interpretación teórica del espacio con respecto al Estado, es decir que este, lejos de su extinción, se adecua para promover y proteger las utilidades económicas de las empresas nacionales y transnacionales e implementar políticas urbanísticas. Los partidos políticos, lejos de reflejar los intereses de la sociedad, facilitan a las empresas los trámites de instalación, licencias, concesiones, permisos, condonándoles y devolviéndoles impuestos y recibiendo cuantiosas sumas de dinero a cambio. Como lo afirma Santos (2001, p. 19), el Estado se ha fortalecido para atender los reclamos de los grandes intereses internacionales en detrimento de los ciudadanos.

De esta manera, el Estado mexicano rompe con el contrato social real e imaginario al proteger a empresas nacionales y transnacionales e inmobiliarias, transgrediendo instrumentos internacionales - a pesar de haberlos firmado y ratificado- en materia ambiental y de derechos humanos, en detrimento de la población urbana y los pueblos originarios de poseer y usufructuar espacios y territorios, el derecho a ser consultados y a reproducirse social, cultural y económicamente. 
Dependiendo del momento histórico, los espacios impactados van adquiriendo características únicas de significación, convirtiéndolos en espacios de lucha, resguardo y resistencia para perpetuar la reproducción de los habitantes ante el embate de la globalización neoliberal y el intento de privatización. Estos lugares son dotados de significado y utilizados como lugares de encuentro, esparcimiento y recreación, generando prácticas colectivas e identitarias.

En este sentido, la Ciudad de México es una ciudad neoliberal porque presenta las características referenciadas por Romero, Brandis y Melo (2015, p. 372), en tanto se priorizan la edificación de nuevas viviendas frente a la rehabilitación, la vivienda como inversión frente a la vivienda como bien de uso, la vivienda libre frente a la vivienda social, la vivienda en propiedad frente a la vivienda en alquiler y la rentabilización a través de plusvalías. Desde la perspectiva de Monreal (2016, p. 100), este tipo de ciudades presentan un incremento en las dinámicas de estigmatización e invisibilización de la miseria, la gentrificación residencial de los centros históricos, las suburbanización en núcleos habitacionales cada vez más cerrados sobre sí mismos y más vigilados.

\section{CASOS EMbLEMÁTICOS DE IMPACTOS A LOS ESPACIOS URBANOS}

Como se ha venido señalando, algunos proyectos involucran la expulsión de personas de sus unidades habitacionales, colonias y barrios, implicando una reorganización espacial, laboral y de actividades económicas. Además, se les arrebatan parques públicos, espacios de recreación, módulos comunitarios 5 , instalaciones y centros deportivos. Para Brites (2017, p. 574), este modelo se ha caracterizado por la inversión selectiva de obras en áreas urbanas, implementación de nuevas legislaciones de ordenamiento y renovación urbana, generación de entornos urbanos embellecidos, promoción turística, facilidades al mercado inmobiliario y políticas habitacionales.

Para que los proyectos urbanos y reordenamientos territoriales operen, las inmobiliarias nacionales y transnacionales necesitan de ciertas condiciones legales (normatividades, reglamentos y leyes). Los gobiernos (federal, estatal, delegacional), a espaldas de los ciudadanos, han modificado el cambio de uso de suelo, que se produce cuando los terrenos son utilizados para otras actividades a las que tradicionalmente estaban asignadas. Por ejemplo, un terreno agrícola en las delegaciones Milpa Alta, Tláhuac y Xochimilco puede ser utilizado para

\footnotetext{
5 Un centro o módulo comunitario es una instalación donde se realizan actividades lúdicas, deportivas y culturales para la población que habita una colonia o barrio, están administradas por las delegaciones.
} 
la industria, comercio, turismo y vivienda. Los factores que motivan el cambio son múltiples: industrias, urbanización, uso de tecnología y fertilizantes, aumento del precio de la tierra, la cercanía a una zona comercial, la implementación de desarrollos inmobiliarios, hoteles, complejos industriales, zonas de desarrollo económico-comercial; cada uno ejerce impactos a corto, mediano y largo plazos. El cambio de uso de suelo es el principal factor de deforestación.

Para implementar proyectos urbanos se presiona a empresas familiares (micro y mediana) para que vendan sus inmuebles a las franquicias; se aumentan los impuestos de predial, agua y luz, esta estrategia ha sido utilizada por el Gobierno capitalino en las calles del centro histórico de la Ciudad de México.

\subsection{Zonas de desarrollo económico y social (Zodes) en Ciudad de México: proyectos en espacios urbanos y estrategias de defensa}

El modelo neoliberal se plasma claramente en las políticas urbanísticas de la Ciudad de México a través del intento de implementación de las zonas de desarrollo económico y social (Zodes) que ha empujado al cambio en las normatividades sobre el uso de suelo y otras disposiciones reglamentarias. Estas forman parte de la política urbana establecida en el Programa General de Desarrollo del Distrito Federal o Ciudad de México 2013-20186. El documento sintetiza que el megaproyecto busca construir una ciudad compacta, policéntrica, dinámica integrada mediante vocaciones económicas, productivas y territoriales. Incluye la identificación de rezagos en materia de servicios urbanos y la identificación de potenciales económicos inmobiliarios, a partir de los cuales se pueda generar inversión productiva, así como la definición de estrategias de desarrollo social que contribuyan al posicionamiento de las Zodes como instrumento impulsor del desarrollo de actividades económicas, sociales y urbanas que permitan elevar la calidad de vida de los ciudadanos. Busca generar vocaciones productivas específicas que atraigan la participación de asociaciones estratégicas compuestas por el sector público y privado, a través de mecanismos de concertación e inducción que materialicen dentro de dichas áreas un entorno diverso. La intención es que en espacios productivos cohabiten centros de innovación, servicios, equipamiento y espacio público, mejorando la calidad de vida del entorno y ofreciendo nuevas oportunidades de empleo para una sana competitividad social y territorial.

6 El programa fue parte de la política urbana encabezada por Miguel Ángel Mancera, jefe de Gobierno de la CDMX de 2013 a 2018. 
Según el Gobierno de la Ciudad de México, las Zodes son áreas que se desarrollan por asociaciones estratégicas cuyas condiciones de ubicación, usos de suelo, equipamientos y otros activos intangibles del Gobierno, al aplicar una vocación productiva, potencian y generan inversión e infraestructura social para recuperar, urbanizar, redensificar sustentable y cualitativamente la zona, con servicios públicos, dotándola de conectividad y movilidad para elevar el valor patrimonial de sus habitantes.

Las Zodes están basadas en el modelo urbanístico de ciudades policéntricas, definidas por una nueva redistribución y reorganización de los espacios urbanos, que implican la privatización de espacios públicos y el incremento en las tarifas de servicios de agua, predial $^{7}$, luz, gas, lo que, en determinado momento, orilla a los habitantes a vender sus predios ${ }^{8}$, casas y departamentos a inversionistas nacionales y extranjeros, lo anterior se convierte en un mecanismo de expulsión y segregación socioespacial. Además, se contemplan colocar parquímetros y el uso de la bicicleta no está considerado. Se trata de crear ciudades dentro de la metrópoli mexicana que tendrán su propio concepto y funciones específicas. Las Zodes se implementarán en todas las delegaciones e incluyen los siguientes proyectos: a) Ciudad Salud, b) Ciudad Administrativa, c) Ciudad Verde, d) Corredor Cultural Creativo y/o Proyecto Corredor Cultural Chapultepec, e) Ciudad Futuro. En todos ellos se contemplan áreas de influencia con el objetivo de abarcar la totalidad de la ciudad.

\section{a) Ciudad Salud}

Ciudad Salud busca expropiar terrenos en zonas habitacionales, es decir, despojar de sus propiedades a los habitantes. Este magno proyecto contempla la construcción de nueve hospitales privados y uno público, departamentos, hoteles, estacionamientos y la ampliación del hospital Médica Sur, que afectará a ocho colonias de la delegación Tlalpan: San Lorenzo Huipulco, Belisario Domínguez, Barrio del Niño Jesús, Toriello Guerra, Pueblo Quieto, Santa Úrsula, Cantera Puente de Piedra y Ampliación Isidro Fabela.

El proyecto se pretende construir al sur de la Ciudad de México, en la zona de hospitales de la delegación Tlalpan. Los habitantes se han manifestado en contra por las siguientes razones: el alza de los precios del predial y otros servicios, la modificación del uso de suelo en algunos predios, el despojo del centro comunitario, el cual pretenden convertirlo en un gimnasio privado.

\footnotetext{
El predial es un impuesto implementado por los gobiernos estatales de México que los ciudadanos deben pagar por concepto de propiedad privada de un bien inmueble.

8 En México se le denomina predio a un terreno donde no se ha construido una casa o vivienda.
} 
En octubre de 2014, los habitantes de Los Pedregales se manifestaron frente a la Asamblea Legislativa del Distrito Federal (ALDF) contra las Zodes y exigieron a la Asamblea convocar a un foro para explicar públicamente a los habitantes en qué consisten los proyectos y sus impactos. El Gobierno de la Ciudad de México no ha cumplido con el derecho que tienen los ciudadanos a ser informados sobre los megaproyectos (como las Zodes), iniciativas y cambios en las normatividades, reglamentos y leyes.

Como sucede en los procesos de implementación de proyectos, algunos habitantes de la Ciudad de México están a favor de estos. Mientras tanto, los opositores señalan que el Gobierno no está pensando en el bienestar de la sociedad y temen que pronto lleguen constructoras y empresas que los despojen de sus predios y casas o los presionen para venderlos. No descartan la posibilidad de la expropiación por concepto de utilidad pública. Los afectados por el proyecto Ciudad Salud señalaron que no se realizó una consulta pública previa, como lo establece la Ley de Desarrollo Urbano y su reglamento para el Distrito Federal. De ahí que, han solicitado suspender cualquier obra pública o privada hasta que no se realice dicha consulta. En este contexto, vecinos y habitantes de las colonias que serán afectados se han aglutinado en el Frente Ciudadano contra las Zodes y en el Movimiento Popular de Pueblos y Colonias del Sur — apoyados por la sociedad civil, estudiantes, académicos e investigadores-, y han iniciado jornadas para difundir los problemas surgidos en torno a los desarrollos inmobiliarios y las Zodes.

\section{b) Ciudad Administrativa}

En el año 2014 se dio a conocer el proyecto que contemplaba la construcción de oficinas de gobierno, viviendas, centros comerciales, torres de departamentos y oficinas en la colonia Doctores de la delegación Cuauhtémoc. Esta es una de las zonas con mayor actividad comercial y administrativa, ahí se genera gran actividad productiva y empleos, convirtiéndolo en un sistema microeconómico funcional con amplios beneficios diarios. La propuesta del ex jefe de gobierno de la ciudad, planteada en la Gaceta Parlamentaria de la Cámara de Diputados, es repoblar con inversión privada, cambiando los rubros comerciales históricamente establecidos por "unos más convenientes», es decir que beneficien a los que tengan recursos para comprar e invertir en el proyecto (Cámara de Diputados, 2015).

¿Qué va a pasar con los habitantes y comerciantes que viven y trabajan en la zona? El proyecto contempla expulsarlos. En su momento, la Secretaría de Desarrollo Urbano y Vivienda (Seduvi) del Gobierno de la ciudad lo promovió 
y paralelamente se incrementaron los costos de servicios de luz, agua y gas. Con el fin de patrocinar y promover un esquema de inversión pública y privada, el argumento utilizado por los funcionarios es que es una colonia antigua y decadente. En la Gaceta Parlamentaria se menciona que son las inmobiliarias las que están detrás del megaproyecto y dictan la agenda para el Desarrollo Urbano de la Ciudad de México, ocasionando que el Gobierno de la ciudad se retire de sus responsabilidades. También se menciona que el ex jefe de gobierno utilizó la narrativa de mejoramiento urbano para ganar adeptos, sin embargo, lo que está detrás es el despojo del patrimonio inmobiliario en una zona de alta demanda inmobiliaria (Cámara de Diputados, 2015). Al cierre de este artículo (septiembre de 2018), el Gobierno de la Ciudad de México no ha otorgado información suficiente a los pobladores.

\section{c) Ciudad Verde}

Ciudad Verde, también denominado Programa Ecoturístico para los Pueblos Originarios de Xochimilco, Magdalena Contreras y Tlalpan en Ciudad de México, forma parte de las Zodes. En palabras del Gobierno, este proyecto busca la defensa del suelo de conservación, los bienes naturales y la propiedad social de los pueblos, lo que implica cambiar el uso de suelo. El 17 de junio de 2014 el Fondo Nacional de Fomento al Turismo (Fonatur), la Secretaría de Desarrollo Rural y Equidad para las Comunidades (Sederec) y el Gobierno firmaron un convenio para otorgar asistencia técnica en materia de planeación turística a los pueblos. El proyecto fue elaborado por la empresa Anaya Amor Arquitectos, S.A. de C.V., para implementar actividades y servicios turísticos acordes a la situación actual y de acuerdo a los requerimientos del mercado. Se realizó un diagnóstico sobre uso de suelo, tipo de tenencia de tierra, nombre de propietarios, costo de tierras. Se contempla establecer reservas territoriales viables para actividades ecoturísticas, infraestructura urbana y de equipamiento, cambio de uso de suelo, venta y expropiación de tierras ejidales ${ }^{9}$, así como parquímetros.

Otro de los objetivos que busca la Ciudad Verde es que los pueblos originarios cuenten con una marca registrada ante el Instituto Mexicano de la Propiedad Industrial. Se pretende integrar a los organismos público, privado

\footnotetext{
9 En México existen tres tipos de propiedad de la tierra: a) privada, b) comunal, c) ejidal. Este último tiene un uso colectivo, es decir, son los ejidatarios que mediante asamblea o reunión deben decidir cómo se usufructuará. Los ejidos emanan de la revolución mexicana y el derecho a la tierra. Antes de la reforma al artículo 27 constitucional en 1992, estos no podían vender, rentar, embargar, enajenar. Posterior a la modificación de ley, entran a la lógica del mercado de tierras, es decir que pueden venderse o rentarse.
} 
y social para administrar el programa, los recursos y la inversión. Ante este posible escenario de implementación e intento de privatización de dichas zonas (pueblos originarios) se creó la Coordinadora de Pueblos del Sur, que aglutina a habitantes y organizaciones sociales de los pueblos que serán impactados.

Algunos sectores de la sociedad en la Ciudad de México exigen un cambio en la política urbana, la cancelación de los parquímetros y la no privatización de espacios públicos y áreas verdes, que son los pocos pulmones que le quedan a la metrópoli. Las entidades ambientales de la Ciudad de México que deben proteger el medio ambiente han permitido ecocidios, a pesar de que los árboles son un mecanismo de mitigación contra el cambio climático, como está asentado en la COP 11 (Conference of the Parties, por sus siglas en inglés) ${ }^{10}$ de 2005, celebrada en Montreal.

El Gobierno de la Ciudad de México pretende imponer los proyectos sin consultar a la ciudadanía o alterando las consultas, como sucedió con el incremento de la tarifa del metro ${ }^{11}$, que, como se había anunciado, no reflejó mejoras significativas y no se adquirieron nuevas unidades para mejorar el servicio. La empresa Calidad de Vida, Progreso y Desarrollo fue la constructora y es la que está gestionando e impulsando tres proyectos de las Zodes (Ciudad Salud, Ciudad Futuro y Corredor Cultural Creativo).

\section{d) Corredor Cultural Creativo o Corredor Cultural Chapultepec}

El proyecto Corredor Cultural Chapultepec de las Zodes fue cancelado en diciembre de 2015. A través de un proceso turbio, el Gobierno de la Ciudad de México pretendía la privatización de espacios públicos con el fin de implementar zonas comerciales en un segundo piso. Este proyecto impactaría a las colonias Chapultepec, Roma, Condesa y Juárez de la delegación Cuauhtémoc. Estas colonias conservan edificios que son patrimonio de la humanidad, que guardan y contienen etapas de la historia de la ciudad. Estos lugares, cargados de significado y simbolismo, son un referente histórico y otorgan identidad urbana y pertenencia a sus habitantes. En este artículo se retoma la definición de identidad colectiva propuesta por Portador (2017, p. 98), en tanto se constituye a partir de referentes culturales. La identidad posibilita que los individuos

\footnotetext{
10 La Conferencia de las Partes (COP) es el órgano supremo de la Convención Marco de las Naciones Unidas sobre el Cambio Climático, y está conformada por representantes de los Estados miembros, agencias de las Naciones Unidas, organismos intergubernamentales y representantes de la sociedad civil.

11 A las personas que les expropiaron sus terrenos para realizar la línea 12 (dorada) del metro, se les dio un pago irrisorio por indemnización y a otros no se les ha pagado. En el proceso de construcción imperó la corrupción en todos los niveles, ello obligó a la suspensión temporal del servicio, que se ha traducido en choques de trenes que no se habían presentado antes.
} 
compartan códigos culturales, instituciones, historia, memoria, valores, pautas de conducta, lealtad, sentido de pertenencia, y al mismo tiempo generen prácticas y acciones colectivas para conseguir ciertos objetivos.

En el caso analizado, las prácticas y acciones colectivas construidas por la sociedad civil, organizaciones sociales, defensores de derechos humanos, urbanistas, arquitectos y afectados por proyectos se aglutinan a partir de referentes y demandas comunes con el objetivo de conseguir detener la privatización de espacios, la expulsión de habitantes, la construcción de megaproyectos, entre otros. Por ejemplo, los habitantes que serían afectados por el Corredor Cultural Chapultepec presionaron y protestaron debido a que serían expulsados al privatizar la zona, por ello exigieron una consulta pública, que se realizó en diciembre de 2015, donde el $65 \%$ rechazó el proyecto y ganó el «no a la construcción del corredor». Este movimiento civil se dio a conocer por diversos medios nacionales e internacionales.

\section{e) Ciudad Futuro}

Ciudad Futuro o Parque Innovación CDMX fue cancelado en enero de 2016. Contemplaba la instalación de empresas relacionadas con la ciencia y la tecnología, y se construiría en predios de las colonias Ajusco Huayamilpas, Parque Huayamilpas, Deportivo Huayamilpas, Candelaria, El Reloj, Adolfo Ruiz Cortines, Pedregal de Santo Domingo en la delegación Coyoacán, y en delegación Tlalpan en las colonias Pedregal de Carrasco, El Caracol, Colonia y Viejo Ejido de Santa Úrsula, y específicamente en el terreno donde se localiza la planta de asfalto, afectando a 19814 viviendas, es decir, una población de 70 226. También incluiría la construcción de un pozo profundo que suministraría agua. El proyecto reduciría y privatizaría espacios públicos como parques y áreas verdes, provocando daños ambientales. Los habitantes solicitaron se derogara la desincorporación del predio Planta de Asfalto, que el Gobierno de la Ciudad de México otorgó a título gratuito a la empresa paraestatal Calidad de Vida, Progreso y Desarrollo para la Ciudad de México S.A. de C.V.

En el Informe de Observaciones de Auditoría del Gobierno de la Ciudad de México, con fecha 16 de diciembre de 2016, se menciona que el proyecto carece de nombre y firma del servidor público responsable del Proyecto Ciudad Futuro, además se presenta como un proyecto de coinversión. Los auditores señalan que el proyecto carece de una adecuada integración del expediente de proyecto, se observa la ausencia de un dictamen con razones técnicas, financieras y jurídicas que justifiquen inversión, factibilidad jurídica, factibilidad técnica, modelo de negocio, justificación jurídica. Lo anterior fue explicitado por la Contraloría General de la Ciudad de México (2016). 
En mayo de 2015, diversos locatarios y comerciantes de los mercados públicos de la delegación Coyoacán protestaron por la implementación del proyecto, y el Gobierno envió cuerpos de granaderos y policías «especializados» para reprimir protestas urbanas. Los manifestantes hicieron diversas demandas, entre las cuales destacaron implementar parques públicos y centros comunitarios sociales, culturales y deportivos en donde se contemplaba construir Ciudad Futuro.

\section{IMPACTOS EN ESPACIOS URBANOS TRAS LOS SISMOS DEL 7 Y I9 DE Septiembre de 2017 en Ciudad de México}

El 7 y 19 de septiembre de 2017, México vivió dos sismos (8,1 y 7,1 grados respectivamente) que afectaron a entidades del sur y centro del país, particularmente Oaxaca, Puebla, Morelos, Estado de México, Chiapas y Ciudad de México, que causaron más de 300 muertos, miles de lesionados y damnificados, pérdida total o parcial de casas, edificios, departamentos y negocios.

El fenómeno natural visibilizó las problemáticas en la urbe, una de las más pobladas del mundo e impactadas por el boom inmobiliario de los años 2000 a 2018, incentivado por los gobiernos de la Ciudad de México. Otros factores a considerar son las condiciones geográficas, ya que está asentada en un lago; el peso de los edificios departamentales y de negocios que se están construyendo provoca grandes socavones, hundimiento de la ciudad y grietas en casas y edificios; también presenta sobreexplotación de acuíferos ya que la demanda de agua es considerable. Presenta serios problemas de falta de servicios públicos, acumulación de basura en algunas zonas, deficiente y contaminante servicio de transporte público; aumento anual del parque vehicular incentivado por los gobiernos, en contubernio con las transnacionales automotrices.

En las últimas décadas, el desarrollo urbano implementado por los gobiernos de la Ciudad de México ha estado marcado por la extinción de espacios públicos y de acceso gratuito a ciudadanos; tala inmoderada de árboles (ecocidios) para incentivar la construcción de líneas de metro y metrobús, hoteles, condominios, torres corporativas, centros comerciales, edificios residenciales y departamentales.

Los sismos mostraron la corrupción de las autoridades delegacionales de los diversos partidos políticos de la Ciudad de México, quienes se prestaron a los sobornos de las inmobiliarias para conseguir permisos ilegales, cambio de uso de suelo y evitar el cumplimento de las normas mínimas de construcción como parte de la política urbanística para incentivar el mercado inmobiliario bajo el amparo de leyes que, desde el año 2000, han permitido la construcción de edificios en las delegaciones, justificando la propuesta de un crecimiento vertical. 
De 2000 a 2006, el Gobierno de la ciudad promovió la normatividad denominada Bando 2 con el objetivo de repoblar principalmente el centro histórico, a este mecanismo se denomina reurbanización de las ciudades neoliberales. De 2006 a 2012 emitió la Norma 26 para la construcción de viviendas de interés social a bajo costo, sin embargo, una vez construidas, las empresas elevaron los precios, quedándose con jugosas ganancias. En 2010 modificó la Ley de Desarrollo Urbano que ampara dichas prácticas, beneficiando a inmobiliarias. De 2012 a 2018 impulsó la construcción de edificios en grandes extensiones a través de fideicomisos reservados, y con ello se propusieron las zonas de desarrollo económico y social (Zodes).

Las delegaciones, la Seduvi y el Instituto de Verificación Administrativa (Invea) de la ciudad, encargadas de vigilar las obras, recibieron sobornos millonarios a cambio de evitar declarar que las empresas no estaban cumpliendo con las normas de construcción, calidad de materiales, viabilidad, seguridad estructural y Atlas de Riesgo. A lo anterior se suma la poca disponibilidad de las autoridades para entregar a los ministerios públicos los documentos, planos, fotografías, expedientes, técnicas de construcción, que las empresas entregaron como parte de la documentación para el trámite de permisos, lo que demuestra negligencia de parte de estas.

Los sismos visibilizaron la ausencia de una política urbana con rostro humano y la falta de planificación de viviendas. Por ejemplo, un gran número de condominios, edificios y casas derribados por los sismos fueron construidos con material de mala calidad, provocando la muerte y el desplazamiento de miles de personas que se quedaron sin vivienda y buscaron refugio con familiares, otros están rentando y en el peor de los casos viven a la intemperie, en campamentos habilitados en la calle. La gran mayoría interpuso demandas contra empresas constructoras e inmobiliarias, y en este sentido han tenido poco o nulo respaldo de las autoridades de la Ciudad de México, ya que las mismas facilitaron y aprobaron los permisos de construcción.

El proceso de demanda requiere una serie de trámites, lo que implica que los afectados deben reunir todos los documentos probatorios. Hay que tomar en cuenta que muchos perdieron todo, y les ha sido difícil recuperar sus bienes y documentos personales. En otros casos, los familiares interpusieron denuncias por homicidio contra los propietarios de aquellos edificios que habían sido evaluados años atrás por la Secretaría de Desarrollo Urbano y Vivienda (Seduvi) de la Ciudad de México y que contaban con dictámenes negativos que determinaban no arrendarlos, debido a que no cumplían con las normas de construcción y las estructuras no eran adecuadas. 
Muchas inmobiliarias, como la Canadá Building, responsable de la construcción de varios edificios desplomados, han sido demandadas. Otras, como Parque Central Residencias, Dekha Asociados, Parque Residencial San Antonio, Residencia Insurgentes Norte y Desarrolladora Vertical Homes, aparecen en los archivos del Gobierno como empresas beneficiadas por este, al otorgarles permisos para construcción.

Las delegaciones de la ciudad con mayores afectaciones son Benito Juárez, Tlalpan, Cuauhtémoc, Xochimilco, Coyoacán, Iztapalapa y Tláhuac. A pesar de los estragos derivados del sismo, continúa la construcción de grandes edificios, principalmente en colonias que el Atlas de Riesgo determina como zonas peligrosas para construir, debido a los impactos negativos provocados por sismos, por inundaciones, desbordamientos de ríos u otros afluentes. El Gobierno de la ciudad continúa incentivando la construcción con el aval de la Secretaría de Desarrollo Urbano y Vivienda. Mientras que la Procuraduría Ambiental y de Ordenamiento Territorial de la Ciudad de México sigue respaldando la tala inmoderada de árboles (ecocidios), lo que a la postre ha generado diversas protestas urbanas. Como resultado de las afectaciones del sismo, los movimientos urbanos de damnificados aglutinados en distintos comités han exigido a las autoridades se modifique el presupuesto, se destinen amplias partidas presupuestales y se otorguen recursos a fondo perdido.

\section{REFLEXIONES FINALES}

El modelo neoliberal ha generado transformaciones urbanas, sociales, políticas, ambientales y espaciales, impactando negativamente a la Ciudad de México. La característica principal del modelo implementado es la segregación socioespacial, la relegación de los habitantes en la toma de decisiones, políticas urbanísticas verticales que favorecen a las empresas e inmobiliarias y la privatización de espacios públicos.

Para que los proyectos urbanísticos e inmobiliarios se instalen y entren en operación se requiere transformar las normatividades y leyes que modifiquen el cambio de uso de suelo, penado por el Panel Intergubernamental del Cambio Climático (IPPC, por sus siglas en inglés) por ser uno de los principales factores que inciden en el calentamiento global. Los estudios de impacto ambiental suelen ser sesgados y no consideran las externalidades negativas, costos externos y ocultos en materia de daños ambientales, cambio climático e impacto en la salud humana. 
La población urbana se ha unificado para la defensa de espacios y territorios, aglutinando diversas demandas, como la defensa de los espacios públicos, unidades habitacionales, mercados y parques; la oposición a la construcción desmedida de desarrollos inmobiliarios y comerciales; y a los cambios de uso de suelo para proyectos y complejos urbanos. Las acciones colectivas enmarcadas en estrategias son multifacéticas, dependiendo del proyecto y la fase en que se encuentra: cierre de calles y avenidas, marchas, plantones, caravanas, retención de funcionarios de gobierno, bicicleteadas, ocupación de oficinas gubernamentales, campańas para no votar. Realizan foros, congresos y denuncias, ingresan expedientes en entidades nacionales e internacionales, donde señalan inconsistencias, despojos e impactos negativos al medio ambiente y a la salud, así como demandas contra empresas e inmobiliarias.

Los grupos ambientalistas han tenido un papel importante, sus acciones y denuncias han obligado a la Procuraduría Federal de Protección al Ambiente (Profepa) de México a realizar nuevas inspecciones, diagnósticos y estudios de impacto ambiental. Han solicitado al Estado mexicano que antes de las consultas otorgue a los habitantes información detallada de los proyectos y de los estudios de impacto ambiental. Han enfatizado que las consultas no tengan ninguna relación con los niveles de gobierno. Como lo estipula el principio número 10 de la Declaración de Río sobre el Medio Ambiente y el Desarrollo:

En el plano nacional, toda persona deberá tener acceso a la información sobre el medio ambiente de que dispongan las autoridades públicas, incluida la información sobre los materiales y las actividades que encierran peligro en sus comunidades, así como la oportunidad de participar en los procesos de adopción de decisiones (ONU, 1992).

Los movimientos en defensa de espacios urbanos muestran la crisis de las instituciones, partidos políticos y gobiernos, así como su falta de representatividad. Por otro lado, sus acciones y omisiones generan incertidumbre; demostrando que el Estado ha dejado de promover el mercado interno, se ha retirado de sus obligaciones con los ciudadanos para fungir como garante y promotor de los intereses de empresas nacionales y trasnacionales. Al respecto, Solórzano (2016, p. 76) plantea que el retraimiento del Estado en la era de la globalización neoliberal ha provocado vacíos de poder económico, político, ambiental y social que han sido capitalizados por las transnacionales. Siguiendo esta línea argumentativa, menciona que el gran poder de estas proviene de la falta de regulación en los órdenes económico, político, ambiental y laboral a nivel internacional y en las economías domésticas.

En México, los sismos de septiembre de 2017 mostraron una de las peores facetas del retiro del Estado mexicano en cuanto a la protección y respaldo hacia 
sus ciudadanos. Y de manera similar al sismo de 1985, la falta de una planeación urbana y la corrupción dejan grandes afectaciones humanas y materiales en la Ciudad de México y las diez entidades federativas del país. Durante la tragedia, el gobierno federal, los gobiernos estatales y las delegaciones ordenaron la demolición de edificios, a pesar de la insistencia de los familiares de continuar con la búsqueda ante la posibilidad de encontrar personas con vida. Los grupos de ayuda internacional, expertos en intervención de estructuras colapsadas, que llegaron posterior a los sismos de 2017, fueron limitados en su labor y en algunos casos presionados para que se retiraran de México $^{12}$. El Gobierno mexicano rechazó la ayuda extranjera para el rescate de ciudadanos y la reconstrucción, argumentando que tenía los recursos necesarios. Las autoridades federales y delegacionales pensaron que la puesta en escena de simulacros anuales garantizaba la protección de la metrópoli. Y tal como sucedió en el sismo de 1985, trataron de ocultar la magnitud de la desgracia, no obstante, los medios alternativos ventilaron las corruptelas entre gobiernos, políticos e inmobiliarias, así como la participación de las mismas inmobiliarias en el proceso de reconstrucción ${ }^{13}$.

Al cierre de este artículo, en septiembre de 2018, miles de damnificados viven en campamentos; miles de alumnos toman clases en instalaciones prefabricadas y esperan la reconstrucción de sus escuelas; cientos de edificios no han sido demolidos y en algunos casos las autoridades han pedido a los dueños pagar la demolición y contraer un crédito hipotecario para pagar la reconstrucción de viviendas. En el caso mexicano, se observa lo que Beck (2007) plantea en cuanto a los usos políticos de las tragedias generadas en una sociedad de riesgo.

Lo anterior es una muestra de las decisiones verticales de los gobiernos delegacional y federal en una urbe que reúne las características de una ciudad neoliberal, con respecto al uso del espacio, elaboración e implementación de proyectos, reestructuraciones urbanas, políticas de reconstrucción y reurbanización.

\footnotetext{
12 Cabe destacar que los cuerpos militares, marinos y policiacos de México no están capacitados para actuar en los terremotos y auxiliar a la población civil afectada, así se corroboró en los desastres del año 2017.

13 Posterior a los sismos, partidos políticos y gobiernos se aprovecharon de la necesidad de las personas al embodegar la ayuda donada por la sociedad nacional e internacional, para utilizarla en sus campańas electorales de julio de 2018.
} 


\section{REFERENCIAS}

Beck, U. (2004). Poder y contrapoder en la era global. La nueva economía politica mundial. Barcelona, España: Paidós.

Beck, U. (2007). La sociedad del riesgo mundial. En busca de la seguridad perdida. Barcelona, España: Paidós.

Brites, W. (2017). La ciudad en la encrucijada neoliberal. Urbanismo mercado-céntrico y desigualdad socio-espacial en América Latina. Urbe, 9(3), 573-586. https://doi.org/10.1590/21753369.009.003.ao14

Cámara de Diputados (2015). Gaceta Parlamentaria, año XVIII, núm. 4389-IV, 21 de octubre. México: Cámara de Diputados LXVIII Legislatura.

Contraloría General de la Ciudad de México (2016). Informe de Observaciones de Auditoría del Gobierno de la ciudad de México con fecha 16 de diciembre de 2016. México: Gobierno de la Ciudad de México.

Cuervo, L. (2012). América Latina: metrópolis en mutación. Questiones Urbano Regionales, 1(1), 53-76.

De Mattos, C. (2012). Reestructuración económica y metamorfosis urbana en América Latina: de la ciudad a la región urbana. Questiones Urbano Regionales, 1(1), 77-100.

Escolano, S., López, C. y Pueyo, A. (2018). Urbanismo neoliberal y fragmentación urbana: el caso de Zaragoza (Espańa) en los primeros quince años del siglo XXI. Eure, 44(132), 183-210. https://doi.org/10.4067/s0250-71612018000200185

Garnier, J. (2015). Urbanismo y neoliberalismo en Francia: una regresión interminable. Ciudades, 18(1), 183-196. https://doi.org/10.24197/ciudades.18.2015.183-196

Garrón, L., Gómez, V., Sánchez, R. y Mato, J. (2016). Cádiz un quiero y no puedo en la conformación de la ciudad neoliberal. En Grupo de Estudios Antropológicos La Corrala (coord.), Cartografía de la ciudad capitalista. Transformación urbana y conflicto social en el Estado español (pp. 219-248). Madrid, España: Traficantes de Sueños.

Gobierno de la Ciudad de México (s/f). ZODES. Documento Ejecutivo de Difusión IV. México: Calidad de Vida, Progreso y Desarrollo para la Ciudad de México/ Gobierno de la Ciudad de México.

Hidalgo, R. y Janoschka, M. (eds.). (2014). La ciudad neoliberal. Gentrificación y exclusión en Santiago de Chile, Buenos Aires, Ciudad de México y Madrid. Chile: GeoLibros/Instituto de Geografía Pontificia Universidad Católica de Chile.

Monreal, P. (2016). Ciudades neoliberales: ¡el fin del espacio público? Una visión desde la antropología urbana. QuAderns-e, 1(21), 98-112.

ONU (1992). Declaración de Río sobre el Medio Ambiente y el Desarrollo. Página de la Organización de las Naciones Unidas. Recuperado el 1 de junio de 2017 de www.un.org/spanish/esa/sustdev/ agenda21/riodeclaration.htm

Portador, T. (2017). Identidad, cultura y globalización. Revista de Relaciones Internacionales Ad Universa, 02(14), 92-110.

Raffestin, C. (1979). Pour une géographie du pouvoir. París: Librairies Techniques.

Rodríguez, A. y Rodríguez, P. (2012). Santiago, una ciudad neoliberal. Questiones Urbano Regionales, 1(1), 101-126.

Rodríguez, A., Saborido, M. y Segovia, O. (2012). Violencia en una ciudad neoliberal: Santiago de Chile. Santiago de Chile, Chile: SUR.

Romero, J., Brandis, D. y Melo, C. (2015). El giro neoliberal de las políticas para la ciudad en España. Balance a partir de los ejemplos de Madrid y Valencia. Boletín de la Asociación de Geógrafos Españoles, 69, 369-386. 
Santos, M. (2001). Por uma outra globalização. Do pensamento único ã consciencia universal. Río de Janeiro, Brasil: Editora Record.

Santos, M. (2008). Por uma geografía nova. São Paulo, Brasil: Editora da Universidade de São Paulo.

Santos, M. (2009). Pensando o espaço do homen. São Paulo, Brasil: Editora da Universidade de São Paulo.

Solórzano, O. (2016). Respuestas y desafíos de la sociedad global en la era de la globalización. Revista de Relaciones Internacionales Ad Universa, 01(13), 64-77.

Solórzano, O. y Portador, T. (2016). Paradojas de la energía eólica ¿Alternativa al cambio climático en la Agenda Global? El corredor eólico en el istmo de Tehuantepec, Oaxaca, México. Revista Ambiente y Sostenibilidad, 6, 56-63.

Theodore, N., Peck, J. y Brenner, N. (2009). Urbanismo neoliberal: la ciudad y el imperio de los mercados. Temas Sociales, 66, 1-12.

Vizcaíno, M. y Vizcaíno, P. (2018). Alejandría, una ciudad neoliberal: ultraconcentración, invasión pausada, división social simbólica y franquicias. Estudios demográficos y urbanos, 33(1), 43-78. https://doi.org/10.24201/edu.v33i1.1734 